and J. Selverstone, Contrib. Mineral. Petrol. 83, 348 (1982); (19)].

16. C. R. Vyhnal and C. P. Chamberlain, Am. J. Sci. 296, 394 (1996). At our field locality, there probably was diagenetic exchange that caused the ${ }^{87} \mathrm{Sr} /{ }^{86} \mathrm{Sr}$ of the amphibolite protolith to be increased from about 0.703 (based on the $\mathrm{Nd}$ isotope data) to about 0.705 or 0.706 . The pelite value may also have been affected.

17. The Lebendun Nappe here contains three horizons of garnet amphibolite ( 8 to $15 \mathrm{~m}$ thick) interlayered with pelite. The "pelite" grades from a quartzrich $\left(86 \% \mathrm{SiO}_{2}\right)$ psammite at the contact to a more typical pelite $\left(75 \% \mathrm{SiO}_{2}\right)$ within $\sim 10 \mathrm{~cm}$. The amphibolite contains biotite, which decreases in mode away from the contact, and garnet porphy- roblasts up to $5 \mathrm{~mm}$ in diameter. At the contact, garnets are more sparse and rarely exceed $500 \mu \mathrm{m}$ in diameter. Pelitic garnets continue to decrease in diameter and mode away from the contact, $<200$ $\mu \mathrm{m}$ near the contact and reaching zero after several meters.

18. See www.sciencemag.org/feature/data/1049980.shl for supplementary raw data and analytical methods.

19. D. Vance and R. K. O'Nions, Earth Planet. Sci. Lett. 114, 113 (1992).

20. This is because $K_{\mathrm{Nd}} \gg K_{\mathrm{sr}}$ such that $D_{\mathrm{Nd}}^{*}$ is very small.

21. N. S. Mancktelow, Tectonophysics 215, 295 (1992).

22. J. B. Brady, Am. J. Sci. 283A, 181 (1983).

23. A. R. Kotelnikov, I. V. Chernysheva, M. S. Parmuzina, Geochem. Int. 36, 846 (1998)
24. E. H. Oelkers and H. C. Helgeson, Geochim. Cosmochim. Acta 52, 63 (1988).

25. C. M. Graham, J. W. Valley, J. M. Eiler, H. Wada, Contrib. Mineral. Petrol. 132, 371 (1998); J. L. M. van Haren, J. J. Ague, D. M. Rye, Geochim. Cosmochim. Acta 60, 3487 (1996); E. D. Young and D. Rumble, Geochim. Cosmochim. Acta 57, 2585 (1993).

26. J. V. Walther, J. Geol. 102, 559 (1994)

27. We thank J. J. Ague, J. G. Bryce, and several anonymous reviewers for valuable reviews and discussions, and J. Selverstone and T. Wawrzyniec for assisting in field site selection. Supported by NSF grant EAR9805218 (D.J.D.) and a Berkeley Geochronology Center Fellowship (E.F.B.).

11 February 2000; accepted 21 March 2000

\title{
Spatial Patterns in the Distribution of Tropical Tree Species
}

\author{
Richard Condit, ${ }^{1 *}$ Peter S. Ashton, ${ }^{2}$ Patrick Baker, ${ }^{3}$ \\ Sarayudh Bunyavejchewin, ${ }^{4}$ Savithri Gunatilleke, ${ }^{5}$ \\ Nimal Gunatilleke, ${ }^{5}$ Stephen P. Hubbell, ${ }^{6}$ Robin B. Foster, ${ }^{7}$ \\ Akira Itoh, ${ }^{8}$ James V. LaFrankie, ${ }^{9}$ Hua Seng Lee, ${ }^{10}$ \\ Elizabeth Losos, ${ }^{1}$ N. Manokaran, ${ }^{11}$ R. Sukumar, ${ }^{12}$ \\ Takuo Yamakura ${ }^{8}$
}

\begin{abstract}
Fully mapped tree census plots of large area, 25 to 52 hectares, have now been completed at six different sites in tropical forests, including dry deciduous to wet evergreen forest on two continents. One of the main goals of these plots has been to evaluate spatial patterns in tropical tree populations. Here the degree of aggregation in the distribution of 1768 tree species is examined based on the average density of conspecific trees in circular neighborhoods around each tree. When all individuals larger than 1 centimeter in stem diameter were included, nearly every species was more aggregated than a random distribution. Considering only larger trees ( $\geq 10$ centimeters in diameter), the pattern persisted, with most species being more aggregated than random. Rare species were more aggregated than common species. All six forests were very similar in all the particulars of these results.
\end{abstract}

The spatial dispersion of individuals in a species is central in ecological theory $(1,2)$. Patchiness, or the degree to which individuals are aggregated or dispersed, is crucial to how a species uses resources, to how it is used as a resource, and to its reproductive biology. Spatial patterns have been a particularly important theme in tropical ecology, because high diversity in the tropics begets low densities. Since Wallace (3) noted how difficult it was to find two individuals of the same species, the hyperdispersion of tropical trees has focused much of theoretical tropical ecology.

In 1979, Hubbell (4) published a large study of dispersion of trees in a dry forest in Costa Rica. His results were contrary to Wallace's long-prevailing wisdom and the Janzen-Connell prediction $(5,6)$ that wide dispersion is a defense against predators. Most species were aggregated, so that near neighborhoods of a tree had a higher than average density of conspecifics. Since that study, though, contradictory results have appeared, particularly from Lieberman and Lieberman (7), who found that most species in a wet forest in Costa Rica, as well as from a literature survey, were not aggregated.

Over the past two decades, we have been assembling a long-term, large-scale, global research effort on spatial patterns and dynamics of tropical forests $(8,9)$. An international team has now fully censused six plots in five tropical countries, mapping and identifying every individual of $\geq 1 \mathrm{~cm}$ in stem diameter over 25 to 52 ha at each plot (Table 1). The large plot size is necessary to encompass substantial populations of most tree species in the community. Major goals of this effort have been to examine Janzen-Connell effects, density dependence, and the spacing pattern of individual species.

The six sites represent a wide variety of tropical forests (Table 1). At one extreme, the two plots in Malaysia are in tall, evergreen forest; have no regular dry season; and include over 800 tree and treelet species each. The Sinharaja forest is also very wet and evergreen, but its island setting reduces species diversity. The site in India is in dry forest with a fairly open canopy, grassy understory, and just 70 species; the Thai site is also dry and low in diversity. The single site in Central America is moist forest, structurally quite like the Malaysian sites, but intermediate in climate and diversity. The forests also cover a wide taxonomic range. Four of the Asian sites are dominated by the family Dipterocarpaceae, but few species are shared among them. The Indian and American sites are distinct taxonomically; they are not dominated by a single family and have few (India) or no (Panama) dipterocarps.

We evaluate spatial patterning by examining neighborhoods around individual trees. For each individual, we tallied the number of conspecifics between $x$ and $x+\Delta x$ meters for all $x+\Delta x$ inside the plot. We also calculated the area inside the plot of each of these annuli. The number of neighbors $N_{x}$ and the area $A_{x}$ in each annulus at distance $x$ were then summed over all individuals of a given species. $D_{x}=\Sigma N_{x} / \Sigma A_{x}$ gives the density of neighboring conspecifics as a function of distance from the average individual. This is a biologically meaningful measure of clumping, because it evaluates the conspecific population density in the neighborhood of

${ }^{1}$ Center for Tropical Forest Science, Smithsonian Tropical Research Institute, Unit 0948, APO AA 34002-0948, USA. ${ }^{2}$ Center for Tropical Forest Science, Harvard Institute for International Development and Harvard University, Cambridge, MA 02138, USA. ${ }^{3}$ Silviculture Laboratory, College of Forest Resources, University of Washington, Seattle, WA 98195-2100, USA. ${ }^{4}$ Royal Thai Forest Department, Chatuchak, Bangkok 10900, Thailand. ${ }^{5}$ Department of Botany, University of Peradeniya, Peradeniya, Sri Lanka. ${ }^{6}$ Center for Tropical Forest Science, University of Georgia, Athens, GA 30602, USA. ${ }^{7}$ Center for Tropical Forest Science, Field Museum of Natural History, Chicago, IL 60605-2496, USA. ${ }^{8}$ Osaka City University, Osaka 558-8585, Japan. ${ }^{9}$ Center for Tropical Forest Science, National Institute of Education, Singapore 1025. ${ }^{10}$ Sarawak Forest Department, Kuching, Sarawak 93660, Malaysia. ${ }^{11}$ Forest Research Institute of Malaysia, Kepong 52109, Kuala Lumpar, Malaysia. ${ }^{12}$ Indian Institute of Science, Bangalore 560012, India.

*To whom correspondence should be addressed. Email: ctfs@tivoli.si.edu 


\section{R E P O R T S}

each tree. It is closely related to Ripley's $K$ statistic [called the correlation integral by astronomers when applied, in three dimensions, to the distribution of galaxies (10)], but $K$ is a cumulative distribution, whereas our neighborhood density is a probability density function; that is, $K_{x}$ refers to conspecifics of $<x$ meters from the focal tree, and $D_{x}$ refers to an annulus between $x$ and $x+\Delta x$ meters. Although the $K$ statistic is very popular (11), our approach has the advantage of isolating specific distance classes, whereas $K$ confounds effects at larger distances with effects at shorter distances $(12,13)$.

To compare species with various population densities, we standardized $D_{x}$ by dividing it by the mean density of a given species across the whole plot. We call this standardized index the relative neighborhood density, or $\Omega$. In a perfectly random distribution, $\Omega_{x}=1$ for all distances $x$. Aggregation is indicated when $\Omega_{x}>1$ at short distances, whereas $\Omega_{x}<1$ at short distances indicates spacing at some scale, or hyperdispersion. A great advantage of this standardized statistic is that it is sample-size independent, which allowed us to directly compare species and stem diameter classes and offered a bootstrap method for estimating confidence limits (14). Rare species, with $N<50$ individuals, had to be dealt with carefully, and most of our statistics are based only on species with at least one individual per hectare (15).

Nearly every species was aggregated when all diameter classes of $\geq 1 \mathrm{~cm}$ were included. In the six plots, 1768 species had at least one individual per hectare: 1753 were aggregated at 0 to $10 \mathrm{~m}\left(\Omega_{0-10}>1\right), 1490$ significantly so (95\% confidence limits around $\Omega_{0-10}$ did not include 1); 1759 were aggregated at 10 to $20 \mathrm{~m}$, and 1730 were aggregated at 20 to $30 \mathrm{~m}$ (16). No plot had fewer than $96 \%$ of its species aggregated at 0 to $10 \mathrm{~m}$, and every one of 772 species at Lambir was aggregated. Relative neighborhood density almost invariably declined with distance (Fig. 1): $\Omega_{10-20}<\Omega_{0-10}$ in 1714 of 1768 species, and $\Omega_{20-30}<\Omega_{10-20}$ in 1581 species. Nevertheless, $\Omega$ values in nearby distance classes were highly correlated with one another. Thus, we can use $\Omega_{0-10}$-the mean conspecific density within $10 \mathrm{~m}$ of a tree (relative to the species' overall density) - as a simple measure of the intensity of aggregation of a species.

There was an enormous range in $\Omega_{0-10}$. Most species had values of $<10$, but there were a few species with much higher aggregation. The highest of all among the species with $\geq 1$ individual per hectare, $\Omega_{0-10}=906$, was in Lagerstroemia sp. (Lythraceae) in the HKK plot; 51 of the 59 individuals of this species occurred in a single clump in an area of $400 \mathrm{~m}^{2}$. Nineteen species had aggregation indices over 100, eight at Lambir and four at HKK. These results are dominated by saplings, because the vast majority of trees $\geq 1 \mathrm{~cm}$ diameter are $<10 \mathrm{~cm}$ diameter.

Results hold for larger trees, though. Nearly all species were aggregated when only diameter classes of $\geq 10 \mathrm{~cm}$ were considered. There were 543 species with more than 1 individual per hectare at this size in all six plots, and 488 had $\Omega_{0-10}>1$; for 257 species, the aggregation was significant (16). But aggregation intensity weakened at greater sizes in most species: 321 of 543 had a higher $\Omega_{0-10}$ for all trees than for larger trees and of those with a significant difference, 84 of 102 were more aggregated at the smaller than at the larger size. At BCI, Pasoh, HKK, and Lambir, about two-thirds of the species were more aggregated at the smaller diameter class, but the pattern reversed at Sinharaja and Mudumalai and most species became more aggregated at the larger size. We repeated the analysis for trees of $\geq 30 \mathrm{~cm}$ diameter and again found most species aggregated (16).

Rare species were substantially more aggre- gated than common species at all but the $\mathrm{Mu}-$ dumalai site (17). Median $\Omega_{0-10}$ was 4 to 10 times higher in the rare abundance class than in the commonest classes (Table 2). In the most abundant species, $\Omega_{0-10}<5$, and at BCI and Pasoh mostly $\Omega_{0-10}<2$, whereas in species with fewer than 500 individuals, $\Omega_{0-10}$ typically ranged from 5 to 30 or higher (Fig. 2). This trend held for species as rare as 10 individuals per 50 ha, even though many species had $\Omega_{0-}$ $10=0$ when $N \cong 10$ (15). For $N<10$ individuals, median scores were zero, but arithmetic means were very high. Thus, the rarest species were the most aggregated of all, and across the entire range of abundances (four orders of magnitude), the degree of clumping correlated negatively with species density. These results match Hubbell's conclusion from dry forest in Costa Rica (4) and two previous analyses of the Pasoh plot $(18,19)$. All results from the neighborhood density statistic $\Omega$ were
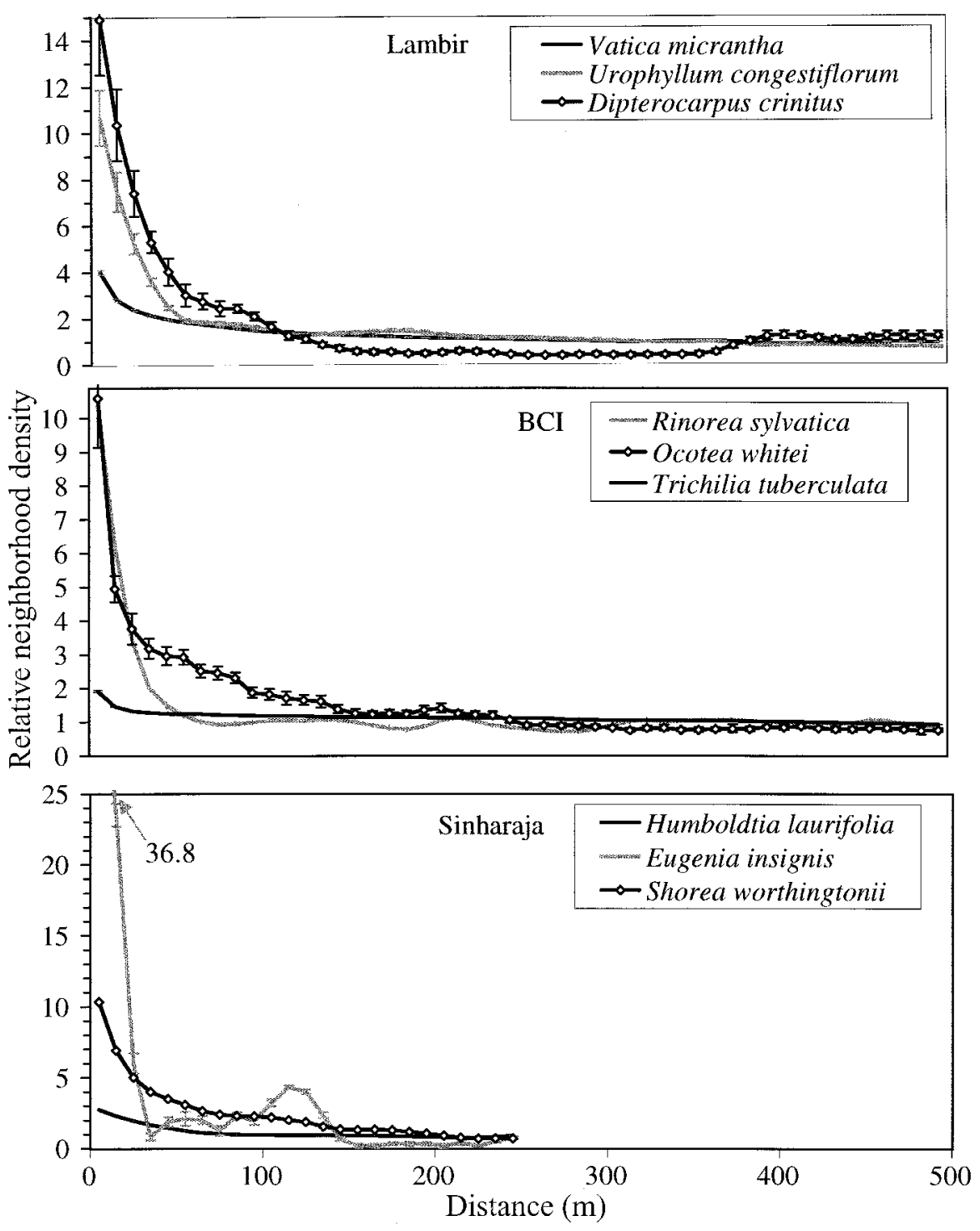

Fig. 1. Relative neighborhood density $\left(\Omega_{x}\right.$ as defined in the text) as a function of distance $x$ in sample species. Vertical bars give $95 \%$ confidence limits (14), sometimes too small to see. 
R E P O R T S

Table 1. Six tropical forest dynamics plots that have been fully censused at least once. Underlined census year is the one used in this report. Dry season months gives the number per year with mean rainfall $<100 \mathrm{~mm}$. dbh, diameter at breast height.

\begin{tabular}{|c|c|c|c|c|c|c|c|c|c|}
\hline Plot & $\begin{array}{l}\text { Plot size } \\
\text { (ha) }\end{array}$ & $\begin{array}{c}\text { Fully } \\
\text { censused }\end{array}$ & $\begin{array}{l}\text { Topographic } \\
\text { variation } \\
\text { (m) }\end{array}$ & $\begin{array}{c}\text { Annual } \\
\text { rainfall } \\
(\mathrm{mm})\end{array}$ & $\begin{array}{l}\text { Dry season } \\
\text { (months) }\end{array}$ & $\begin{array}{c}\text { Species } \\
\geq 1 \\
\mathrm{~cm} \text { dbh }\end{array}$ & $\begin{array}{c}\text { Species } \\
\geq 10 \\
\mathrm{~cm} \text { dbh }\end{array}$ & $\begin{array}{c}\text { Individuals } \\
\geq 1 \mathrm{~cm} \\
\mathrm{dbh}\end{array}$ & $\begin{array}{c}\text { Individuals } \\
\geq 10 \mathrm{~cm} \\
\mathrm{dbh}\end{array}$ \\
\hline $\begin{array}{l}\text { Barro Colorado Island } \\
(\mathrm{BCl}) \text {, Panama }\end{array}$ & 50 & $\begin{array}{c}1981-83 \\
1985 \\
1990 \\
1995 \\
\end{array}$ & 38 & 2500 & 4 & 299 & 226 & 229,071 & 21,459 \\
\hline $\begin{array}{l}\text { Pasoh, Malaysia } \\
\text { (Peninsula) }\end{array}$ & 50 & $\begin{array}{c}1986-89 \\
1990 \\
1995-96 \\
\end{array}$ & 25 & 1800 & 0 & 818 & 673 & 320,382 & 28,997 \\
\hline $\begin{array}{l}\text { Lambir, Malaysia } \\
\text { (Borneo) }\end{array}$ & 52 & $\begin{array}{c}1991-94 \\
1997 \\
\end{array}$ & 140 & 2700 & 0 & 1174 & 996 & 366,121 & 32,962 \\
\hline $\begin{array}{l}\text { Huai Kha Khaeng } \\
\text { (HKK), Thailand }\end{array}$ & 50 & $\underline{1992-94}$ & 89 & 1450 & 6 & 248 & 211 & 81,145 & 21,957 \\
\hline Mudumalai, India & 50 & $\frac{1988-89}{1992}$ & 130 & 1200 & 6 & 72 & 63 & 25,306 & 14,922 \\
\hline
\end{tabular}

Table 2. Median aggregation index, $\Omega_{0_{-10}}$, across species in various abundance categories in the six large plots. Number of species within each abundance category is listed under spp. Last row gives overall median $\Omega_{0-10}$ for all species with at least 50 individuals at each plot.

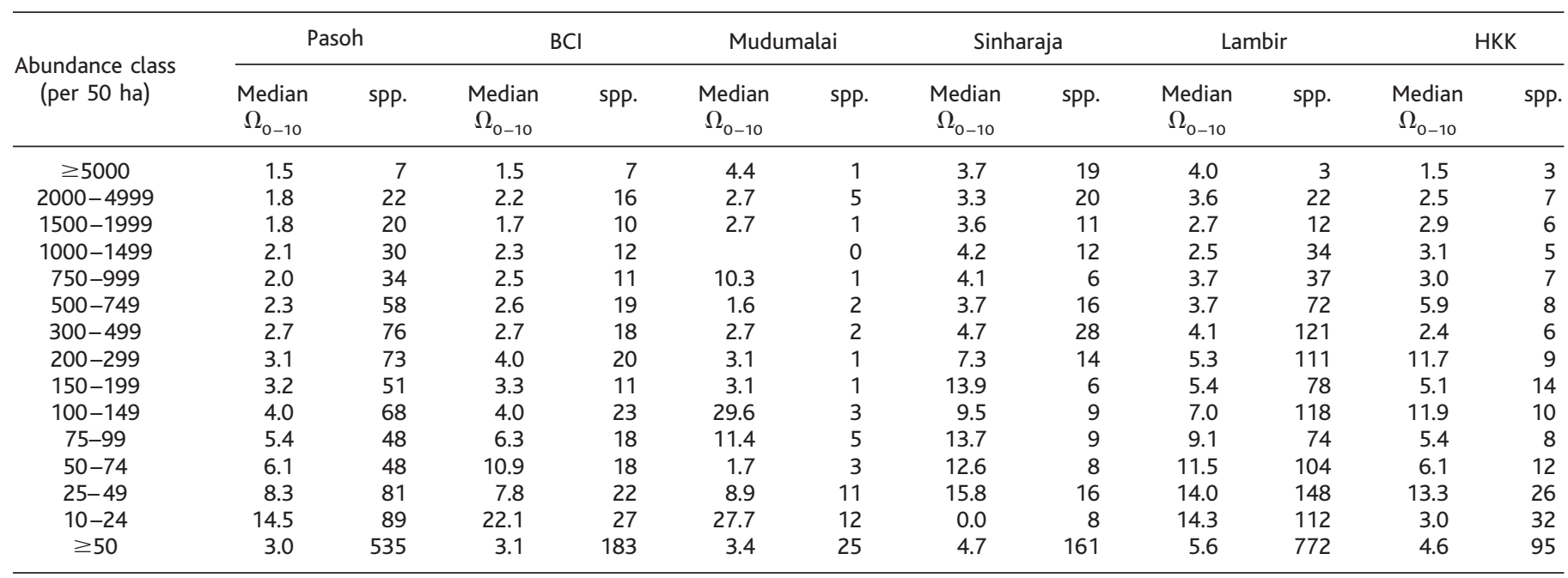

confirmed by nearest-neighbor analysis (16).

The six forests were remarkably similar in community-wide patterns of aggregation. The range of values for $\Omega_{0-10}$ was similar at all sites, and the relationship between this aggregation index and abundance was essentially identical across sites. However, there were significant differences (20). Pasoh and BCI had low aggregation indices at a given abundance, whereas Sinharaja and Lambir had high indices (Table 2). These results correspond with habitat variation within the plots in that Pasoh and BCI are topographically uniform and Lambir and Sinharaja are relatively rugged (Table 1 ). Lambir also has a sharp soil gradient (21). Mudumalai has steep topography, but there is little indication that species respond to it, whereas at Lambir and Sinharaja many species' distributions follow topographic features (22). There are clear exam- ples of habitat-related patchiness at most of the plots, especially Sinharaja (Fig. 3). Species in which larger trees were more densely aggregated than juveniles are also suggestive of habitatrelated patchiness, because adults might be collected in sites most favorable for the species, whereas juveniles are widely dispersed.

On the other hand, there are many species in all the plots whose aggregated distributions indicate dispersal limitation. These species occur in circular clumps that do not correspond with topography (Fig. 3), and they had the highest values of $\Omega_{0-10}$. Their neighborhood density functions $\Omega_{x}$ declined abruptly with distance (Fig. 1). We tested the importance of dispersal limitation by comparing aggregation intensity in poorly versus welldispersed trees. Species whose seeds are dispersed by animals were assumed to be better dispersed than wind- or explosively dispersed species, and canopy trees were assumed to have well-dispersed seeds relative to understory treelets (23). We also considered the Dipterocarpaceae, a family of trees with poorly dispersed, winged seeds that dominates Southeast Asian forests.

The prediction that better dispersal reduces aggregation was partially borne out. There was no significant difference in aggregation intensity between canopy and understory species at Pasoh, but at BCI there was (24). At $\mathrm{BCI}$, there was no significant difference in aggregation for animal versus nonanimal dispersed species, but the difference was fairly pronounced in the predicted direction (25). Finally, at the two Malayasian plots, dipterocarps were strikingly more aggregated than nondipterocarps (26). 
R E P O R T S

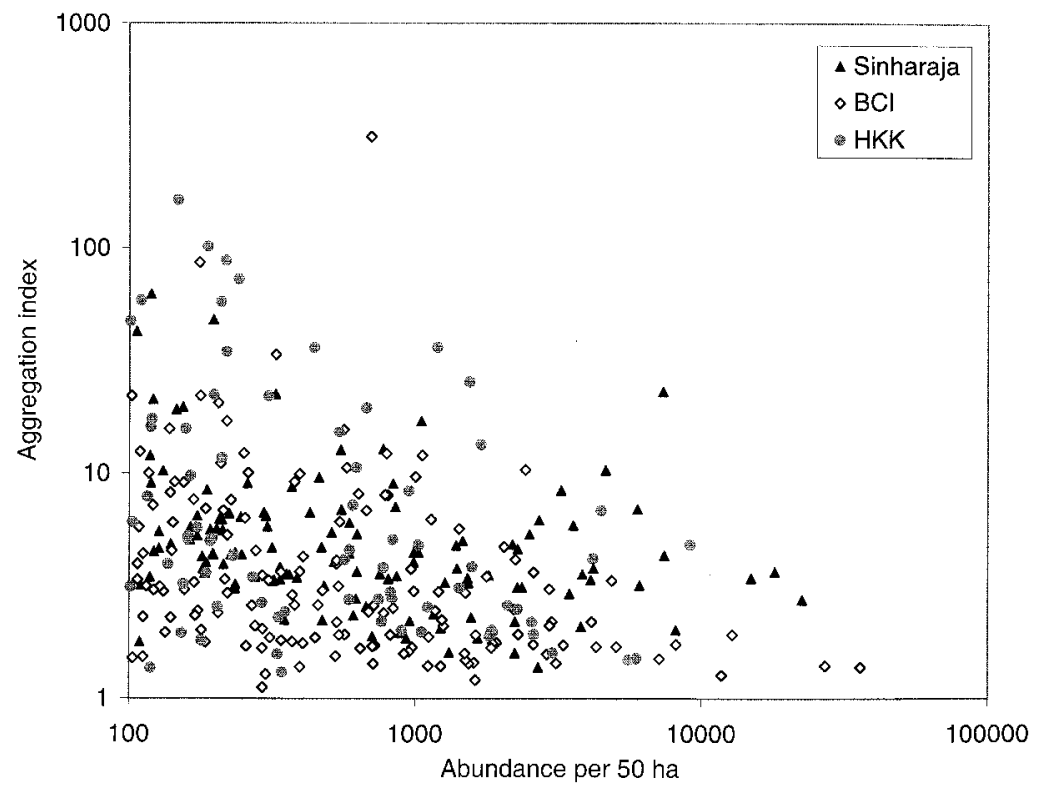

Fig. 2. Aggregation index $\left(\Omega_{0-10}\right.$, the relative density of conspecifics within $10 \mathrm{~m}$ of focal trees) for all species with $\geq 100$ individuals at three plots, as a function of the abundance of each species, on a log-log scale.
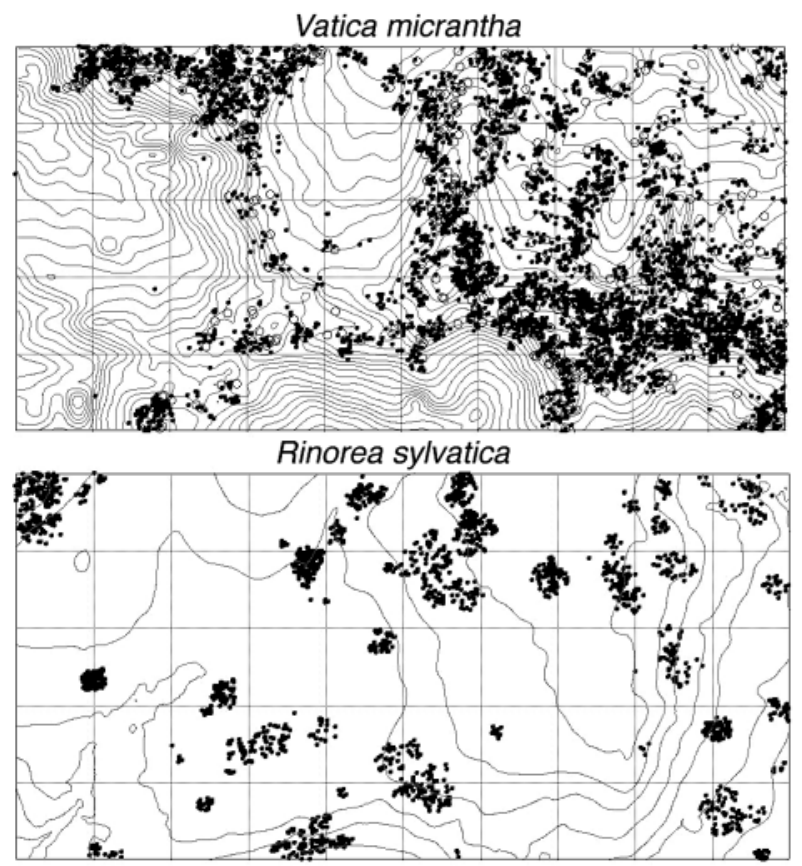

Shorea worthingtonii

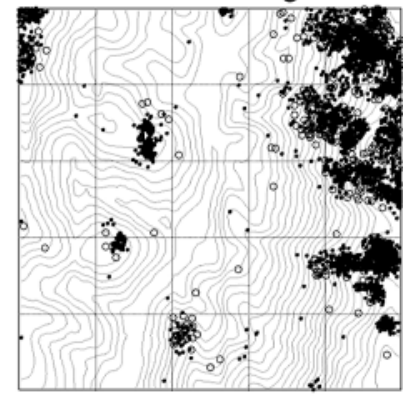

Eugenia insignis

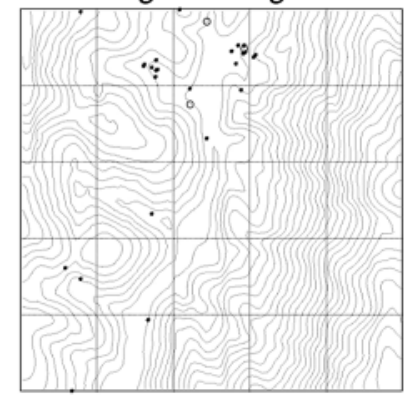

Fig. 3. Distribution maps for species also used in Fig. 1. Small circles, trees of 1 to $9.9 \mathrm{~cm}$ diameter; open circles, trees of $\geq 10 \mathrm{~cm}$ diameter. Grid squares $=1$ ha. Vatica clumps follow ridges at Lambir. Rinorea clumps at $\mathrm{BCl}$ do not correlate with any known canopy, topographic, or soil feature, and the patches are probably due to limited seed dispersal (seeds disperse from exploding capsules). Shorea follows ridge tops at Sinharaja, and Eugenia is very rare at Sinharaja, but most individuals are close to several conspecifics. Additional maps published elsewhere $(32,33)$ illustrate many cases of habitat and dispersal limited patchiness.

Finally, the observation that aggregation is weaker in larger diameter classes supports the notion that herbivores and plant diseases play a role in reducing aggregation. Other evidence from the BCI and Pasoh plots indicates that pests have already substantially weakened aggregation intensity by the time trees enter the census at $1 \mathrm{~cm}$ diameter $(27$, 28). After $1 \mathrm{~cm}$ diameter, the pest effect is not particularly dramatic, and we saw no indication for further loosening of aggregations between 10 - and $30-\mathrm{cm}$ diameters.
References and Notes

1. M. R. T. Dale, Spatial Patterns Analysis in Plant Ecology (Cambridge Univ. Press, Cambridge, 1999).

2. C. L. Folt and C. W. Burns, Trends Ecol. Evol. 8, 300 (1999).

3. A. R. Wallace, A Narrative of Travels on the Amazon and Rio Negro (Haskell House, New York, 1853).

4. S. P. Hubbell, Science 203, 1299 (1979).

5. D. H. Janzen, Am. Nat. 104, 501 (1970)

6. J. H. Connell, in Dynamics of Populations, P. J. den Boer and G. R. Gradwell, Eds. (PUDOC, Waneningen, Netherlands, 1971), pp. 298-312.

7. M. Lieberman and D. Lieberman, in La Selva: Ecology and Natural History of a Neotropical Rain Forest, L. A. McDade et al., Eds. (Univ. of Chicago Press, Chicago, 1994), pp. 106-119.

8. R. Condit, Trends Ecol. Evol. 10, 18 (1995).

9. P. S. Ashton, in Forest Biodiversity Research, Monitoring and Modeling: Conceptual Background and Old World Case Studies, F. Dallmeier and J. A. Comiskey, Eds. (UNESCO and Parthenon Publishing, Paris, 1998), pp. 47-62.

10. V. J. Martinez, Science 284, 445 (1999).

11. P. Haase, J. Veg. Sci. 6, 575 (1995).

12. A. Getis and J. Franklin, Ecology 68, 473 (1987)

13. A. Penttinen et al., For. Sci. 38, 806 (1992).

14. We proved sample-size independence by randomly selecting 100 individuals, without replacement, from all populations and observing no change in $\Omega_{x^{\prime}}$ even for species with as many as 40,000 individuals. There is proof of sample-size independence of this statistic (29). To estimate confidence limits for $\Omega_{x^{\prime}}$ a sample of exactly half the population of each species was drawn at random 15 times, without replacement and, for each, $\Omega_{x}$ was calculated in all $10-\mathrm{m}$ distance intervals. A variance and $95 \%$ confidence limits-based on a $t$ statistic-were calculated from this sample; because the sample was halved, the limits were divided by (2) ${ }^{1 / 2}$ before being applied to the entire sample. We judged statistical significance of aggregation or overdispersion by checking whether confidence limits included 1 and, to compare two different estimates, we checked whether confidence limits overlapped.

15. Even under complete spatial randomness, the probability that $\Omega_{0-10}=0$ is high when $N<50$ in 50 ha. Across all plots, no species with $N \geq 100$ had $\Omega_{0-10}=0$, whereas a few species with 50 to 100 individuals had $\Omega_{0-10}=0$. With $N<10, \Omega_{0-10}=0$ in most species. For this reason, most of our analyses refer to all species with $\geq 50$ individuals in the 50 -ha plots (to standardize density, the cutoff was set at 1 per hectare, or 25 individuals in the Sinharaja plot and 52 in the Lambir plot).

16. Supplementary material is available at www. sciencemag.org/feature/data/1048222.shl.

17. When all stems of $\geq 1 \mathrm{~cm}$ diameter were analyzed, a Spearman rank correlation between $\Omega_{0-10}$ and a species' abundance was significant and negative at all plots but Mudumalai and HKK for species with $N \geq 50$.

18. F. He, P. Legendre, J. V. LaFrankie, J. Veg. Sci. 8, 105 (1997).

19. T. Okuda et al., Plant Ecol. 131, 155 (1997);

20. We compared forests by calculating confidence limits for the mean values of $\log \left(\Omega_{0-10}\right)$ within abundance categories, each species being a single datum, using $t$ statistics. Tests were done separately on all categories listed in Table 2, and significant differences between plots were assumed when 95\% confidence limits did not overlap. Lambir, HKK, and Sinharaja had significantly higher $\Omega_{\mathrm{O}-10}$ than Pasoh and $\mathrm{BCl}$ in at least two abundance categories, and Lambir and Sinharaja were significantly higher than Pasoh in most abundance categories.

21. P. A. Palmiotto, thesis, Yale University, New Haven, CT, 1998.

22. A. Itoh et al., Plant Ecol. 132, 121 (1997).

23. Dispersal mode (wind, animal, or explosive) was estimated from our own experience and from a published account (30). Species were classified as canopy or understory (at their largest size) at $\mathrm{BCl}$ and Pasoh from our experience and from published floras (30, 31). Significance was tested with confidence limits for $\log \left(\Omega_{0-10}\right)(20)$.

24. At Pasoh, the median $\Omega_{0-10}$ for canopy species was 
2.8, and for understory it was 3.1 ; the difference is not significant. At $\mathrm{BCl}$, the medians were 2.9 and 4.2 , and the difference is significant.

25. The median $\Omega_{0-10}$ for wind- or explosively dispersed species at $\mathrm{BCl}$ was 4.5; for animal-dispersed species it was 3.0, but the difference was not significant.

26. At Pasoh, the 24 dipterocarp species with $N \geq 50$ individuals had a median $\Omega_{0-10}$ of 5.1, compared with 2.8 for all other species. At Lambir, 65 dipterocarps had $\Omega_{0-10}=21.8$; for other species, $\Omega_{0-10}=5.3$. Both differences are significant. At Sinharaja, 12 dipterocarps were slightly but not significantly more aggregated than nondipterocarps. HKK and Mudumalai had just three and one dipterocarp species, respectively.
27. C. Wills and R. Condit, Proc. R. Soc. London Ser. B 266, 1445 (1999).

28. K. E. Harms et al., Nature 404, 493 (2000).

29. H. M. Hastings and G. Sugihara, Fractals: A User's Guide for the Natural Sciences (Oxford Univ. Press, Oxford, 1993).

30. T. R. Croat, Flora of Barro Colorado Island (Stanford Univ. Press, Stanford, CA, 1978).

31. T. C. Whitmore, Ed., Tree Flora of Malaya: A Manual for Foresters (Longman, London, 1972).

32. N. Manokaran et al., Stand Table and Distribution of Species in the 50-ha Research Plot at Pasoh Forest Reserve, Research Data (Forest Research Institute of Malaysia, Kepong, Malaysia, 1992), vol. 1.

33. R. Condit, Tropical Forest Census Plots (Springer-
Verlag and R. G. Landes Co., Berlin, and Georgetown, TX, 1998).

34. Supported by the Indian Institute of Science, the University of Peradeniya (Sri Lanka), the Sarawak Forest Department (Malaysia), the Forest Research Institute of Malaysia, the Royal Thai Forest Department, the Smithsonian Tropical Research Institute, the Japanese National Institute of Environmental Studies, the Japanese Ministry of Education and Science, the National Science Foundation, and the John D. and Catherine T. MacArthur Foundation. R.C. thanks J. Franklin's group in the College of Forest Resources at the University of Washington for support during a sabbatical.

23 December 1999; accepted 28 March 2000

\section{Mechanism of ATP-Dependent Promoter Melting by Transcription Factor IIH}

\author{
Tae-Kyung Kim, ${ }^{1}$ Richard H. Ebright, ${ }^{2}$ Danny Reinberg ${ }^{1 *}$
}

\begin{abstract}
We show that transcription factor IIH ERCC3 subunit, the DNA helicase responsible for adenosine triphosphate (ATP)-dependent promoter melting during transcription initiation, does not interact with the promoter region that undergoes melting but instead interacts with DNA downstream of this region. We show further that promoter melting does not change protein-DNA interactions upstream of the region that undergoes melting but does change interactions within and downstream of this region. Our results rule out the proposal that IIH functions in promoter melting through a conventional DNAhelicase mechanism. We propose that IIH functions as a molecular wrench: rotating downstream DNA relative to fixed upstream protein-DNA interactions, thereby generating torque on, and melting, the intervening DNA.
\end{abstract}

Human transcription factor IIH consists of nine polypeptides with masses of 31 to $90 \mathrm{kD}(1-3)$. $\mathrm{IIH}$ is responsible for three critical functions in transcription: phosphorylation of the $\mathrm{COOH}$ terminal domain (CTD) of the RPB1 subunit of RNA polymerase II (RNAPII), promoter melting, and promoter clearance.

IIH-dependent CTD phosphorylation re- quires ATP and is mediated by the IIH cdk7 subunit, which is a cyclin-dependent protein kinase (1-3). The role of IIH in promoter melting is to melt about one turn of DNA encompassing the transcription start site to yield the "transcription bubble" $(4,5)$. This process requires $\operatorname{ATP}(4,5)$ and is mediated by the IIH ERCC3 subunit $(6,7)$ (also referred to as
$\mathrm{XPB})$, which, in isolation, exhibits $3^{\prime}-5^{\prime}$ DNAhelicase activity $(6,8,9)$. The role of IIH in promoter clearance is to stimulate escape of transcription elongation complexes stalled at positions +10 to $+17(10-12)$. Like promoter melting, promoter escape requires ATP (1013) and is mediated by the IIH ERCC3 subunit (14).

The fact that promoter melting involves generation of single-stranded DNA (ssDNA) and that promoter escape involves a species containing ssDNA, together with the fact that the IIH subunit that mediates these processes exhibits DNA-helicase activity, has led to the proposal that IIH functions in these processes through a conventional DNA-helicase mechanism, with direct interactions between $\mathrm{IIH}$ and ssDNA $(1-3,15)$. However, no direct evidence has been obtained in support of this proposal.

As a first step to understand the mechanism

${ }^{1}$ Howard Hughes Medical Institute, Division of Nucleic Acids Enzymology, Department of Biochemistry, University of Medicine and Dentistry of New Jersey, Robert Wood Johnson Medical School, Piscataway, NJ 08854, USA. ${ }^{2}$ Howard Hughes Medical Institute, Waksman Institute, and Department of Chemistry, Rutgers University, Piscataway, NJ 08854, USA

*To whom correspondence should be addressed. Email: reinbedf@umdnj.edu
Fig. 1. Results of protein-DNA photo-crosslinking experiments. (A) Representative data. TBFR, transcription-complex intermediate containing RNAPII, TBP, IIB, IIF, and promoter DNA (18); TBFRE, TBFR plus IIE; TCC, transcriptionally competent complex, consisting of TBFR plus IIE and IIH; TCC + ATP, transcriptionally competent complex after ATP-dependent CTD phosphorylation and promoter melting. RPB1 and RPB1-Pn denote forms of the largest subunit of RNAPII having unphosphorylated CTD and phosphorylated CTD, respectively. Data are shown for positions $-2,+5,+13$, and +21 of the DNA nontemplate strand. (B) Representative data for experiments assessing NTP specificity (positions $-2,+5$, and +13 of DNA nontemplate strand). (C) Representative data confirming identities of cross-linked IIE $\alpha$ [(left) parallel experiment with IIE $\alpha(1-394)(31,49)]$ and IIH ERCC3 [(right) immunoprecipitation with antibody to ERCC3 of cross-linked polypeptide (32)]. (D) Representative data demonstrating increase in fraction of complexes competent for CTD phosphorylation (top; analysis of electrophoretic mobility of cross-linked RPB1) and transcription [bottom; quantitation of transcription (arbitrary units) and RNAPII content (1.0 unit = $20 \mathrm{fmol}$ RNAPII) upon Sarkosyl washing (24)].
A
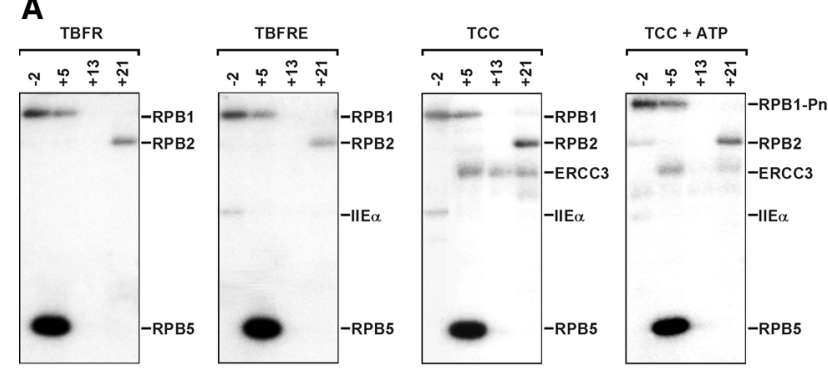

C

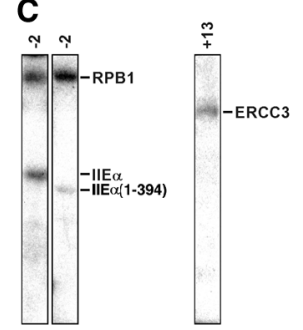

B

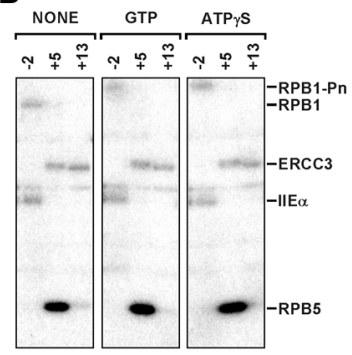

D unwashed

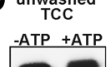

$\underset{\text { TCC }}{\text { Sarkosyl-washed }}$

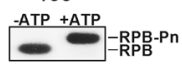

$\underset{\text { TCC }}{\text { unwashed }}$ Sarkosyl-washed
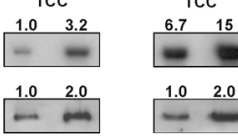

transcription

\begin{tabular}{|ll}
1.0 & 2.0 \\
- & -
\end{tabular} RNAPII (Immunoblotting) 